\title{
Plurilinguismo e Pluriculturalidade: abordagem humanística ${ }_{-}^{1}$
}

\author{
Plurilingüismo y Pluriculturalidad: abordaje humanística \\ Plurilingualism and Pluriculturality: humanistic approach
}

Millene Barros Guimarães de Sousa_2

\begin{abstract}
Resumo
Esta proposta de trabalho fundamenta-se no projeto de pesquisa em vigência no Instituto Federal do Paraná, Campus Avançado Quedas do Iguaçu, no qual atuo como coordenadora, intitulado "Plurilinguismo e Pluriculturalidade: viver, experienciar e ser”. Esse projeto surge da percepção da importância de práticas pedagógicas nas aulas de línguas, materna e estrangeira, voltadas à promoção do saber-fazer e saber-ser do discente em que ele se situe em seu próprio mundo e nos espaços sociais, políticos e culturais de forma crítica e significativa. Os conceitos plurilinguismo e pluriculturalidade convivem no mesmo espaço, principalmente, quando se lança o olhar à realidade escolar heterogêneo, no que tange ao ambiente cultural e linguístico. Ratifica-se a relevância do desenvolvimento de ações que toquem na questão da pluralidade, seja ela cultural, linguística, socioeconômica, étnica, racial, sexual ou política, para que o aprendizado das línguas se torne eficaz, promovendo para um ambiente solidário e democrático. Assim, esse projeto contempla a temática língua, no viés teórico da pluralidade, a fim de que o discente compreenda o conceito língua como uma esfera social, cultural, política, contribuindo para sua vivência, experiência e formação identitária e cidadã na compreensão da sua realidade linguística-cultural materna e variedades, assim como, a realidade linguística cultural de línguas estrangeiras. Este texto apresenta um relato de experiência nos primeiros passos de implementação do projeto com uma proposta relacionada à política para mulheres, desenvolvida no projeto citado, em que o diálogo plural, o respeito à diversidade e a promoção de práticas que proporcione a criticidade do aluno são pilares dessa experiência vivenciada.
\end{abstract}

Palavras-Chave: Pluralidade; Plurilinguismo; Pluriculturalidade; Educação humanista; Sociedade.

\section{Resumen}

Esta propuesta de trabajo surge del proyecto presente en Instituto Federal de Paraná, Campus Avançado Quedas do Iguaçu, que soy coordinadora, llamado "Plurilingüismo y Pluriculturalidad: vivir, disfrutar y ser". Ese proyecto surge de la percepción de la importancia de prácticas pedagógicas en las clases de lenguas materna y extranjera, que plantea la promoción del saber-hacer y saber-ser del alumno en que él se situé en su propio mundo y en los espacios sociales, políticos y culturales de manera crítica y significativa. Los conceptos plurilingüismo y pluriculturalidad conviven en los mismos espacios, principalmente, cuando se lanza la mirada a la realidad escolar heterogénea, en lo que se refiere al ambiente cultural y lingüístico. Se ratifica la relevancia del desarrollo de acciones que toque la cuestión de la pluralidad, ya sea cultural, lingüística, socioeconómica, étnica, racial, sexual o política, para que el aprendizaje de las lenguas se haga eficaz, a promover a un ambiente solidario y democrático. Así, este proyecto contempla la temática lingüística, en el enfoque teórico de la pluralidad, a fin de que el alumnado comprenda el concepto lingüístico como una esfera social, cultural, política,

\footnotetext{
1. Artigo apresentado no Simpósio Temático Diálogos interculturais de fronteiras: perspectivas teóricas e experiências compartilhadas durante o II Seminário Latino-Americano de Estudos em Cultura - SEMLACult em Foz do Iguaçu/PR, Brasil, 2018.

2 Mestre em Letras; Instituto Federal do Paraná - IFPR; Quedas do Iguaçu, Paraná; Brasil; millene.guimaraes@ifpr.edu.br.
} 
contribuyendo a su vivencia, experiencia y formación identitaria y ciudadana en la comprensión de su realidad lingüística-cultural materna y variedades, así como la realidad lingüística-cultural de lenguas extranjeras. Este texto presenta un relato de experiencia en los primeros caminos en la implementación de la propuesta con la acción relacionada a la política para mujeres, desarrollada en el proyecto citado, en que el dialogo plural, el respeto a la diversidad y la promoción de prácticas que proporcione la criticidad del alumno son pilares en esta experiencia.

Palabras claves: Pluralidad; Plurilingüismo; Pluriculturalidad; Educación humanista; Sociedad.

\begin{abstract}
This work proposal comes from the project present in the Federal Institute of Paraná, Campus Avançado Quedas do Iguaçu, which I am a coordinator, called "Plurilingualism and Pluriculturalism: living, experiencing and being". This project arises from the perception of the importance of pedagogical practices in the mother and foreign language classes, which raises the promotion of the know-how and know-how of the teacher in which he placed himself in his own world and in social spaces, politically and culturally in a critical and meaningful way. The concepts plurilingualism and pluriculturalism coexist in the same spaces, mainly, when you look at the heterogeneous school reality, in what refers to the cultural and linguistic environment. The relevance of the development of actions that touch on the question of plurality, whether cultural, linguistic, socioeconomic, ethnic, racial, sexual or political, is confirmed so that the learning of languages becomes effective, contributing to a supportive and democratic environment. Thus, this project considers the linguistic theme, in the theoretical approach of plurality, so that the students understand the linguistic concept as a social, cultural, political sphere, contributing to their experience, experience and identity and citizenship formation in the understanding of their maternal linguistic-cultural reality and varieties, as well as the linguistic-cultural reality of foreign languages. This text presents an account of experience in the first paths in the implementation of the project with the action related to the policy for women, developed in the aforementioned proposal, in which plural dialogue, respect for diversity and the promotion of practices that provide the criticality of the student are pillars in this experience.
\end{abstract}

Keywords: Plurality; Plurilingualism; Pluriculturalism; Humanist Education; Society.

\title{
1. Introdução
}

$\mathrm{O}$ presente trabalho relata as experiências do projeto "Plurilinguismo e Pluriculturalidade: viver, experienciar e ser”, que acontece no Instituto Federal do Paraná Campus Avançado Quedas do Iguaçu, desde março de 2018, com previsão de término, em julho de 2019, principalmente, a experiência da proposta "Pluralidade social: uma abordagem humanística as políticas para mulheres", integrada ao projeto citado.

O projeto surge da percepção da importância de práticas pedagógicas nas aulas de línguas, materna e estrangeira, voltadas à promoção do saber-fazer e saber-ser do discente, em que ele deve se situe em seu próprio mundo e nos espaços sociais, políticos e culturais de forma crítica e significativa. Os conceitos pluri- língua e cultura convivem no mesmo espaço, principalmente, quando se lança o olhar à realidade escolar heterogêneo, no que tange ao ambiente cultural e linguístico. Ratifica-se a relevância do desenvolvimento de um projeto de ensino que toque na questão da pluralidade, seja ela cultural, linguística, socioeconômica, étnica, racial, sexual ou política, para que o aprendizado das línguas se torne eficaz, 
contribuindo para um ambiente solidário e democrático no processo de atravessamento de fronteiras culturais.

Este projeto contempla a temática língua, no viés teórico da pluralidade, a fim de que o discente compreenda o conceito língua como uma esfera social, cultural, política, contribuindo para sua vivência, experiência e formação identitária e cidadã na compreensão da sua realidade linguística-cultural materna e variedades, assim como, a realidade linguísticacultural de línguas estrangeiras.

O projeto justifica-se pela preocupação e a atitude de realizações pedagógicas que aprimorem e contribuam com a formação humanística da comunidade escolar (professores, técnicos e alunos) do Instituto Federal do Paraná, Campus Avançado de Quedas do Iguaçu, no contexto da educação profissional e, também, da comunidade externa.

Dessa forma, os objetivos gerais do projeto pautam-se: (i) no desenvolvimento do pensamento crítico do discente a partir da reflexão da própria percepção de Si e do OUTRO, ao interagir e experienciar a pluralidade linguística e cultural e (ii) na transformação do aluno em ser ativo, como agente social, capaz de refletir de sobre as diferentes realidades (local, regional, nacional e global), cultivando princípios como: a solidariedade, empatia, equidade e responsabilidade.

A proposta "Pluralidade social: uma abordagem humanística as políticas para mulheres", em consonância com o projeto explicitado, fundamenta-se no desenvolvimento de ações voltadas aos Direitos Humanos, afirmando o diálogo pluricultural e plurilinguístico na promoção e difusão das políticas públicas para mulheres a partir da abordagem humanística.

Essa proposta surge da observação local e regional de onde encontra-se o campus, que faltam ações culturais na demanda local e, também, na percepção do conhecimento enciclopédico e de mundo que os discentes expressam nas aulas de língua materna e estrangeira, demonstrando um baixo envolvimento nas ações culturais, e até uma não valorização da competência cultural no processo de sua formação identitária. Consequentemente, constitui-se um ambiente com visão unilateral, propício a intolerância e preconceito, afastando-se do ambiente de pluralidade, heterogeneidade e de diversidade. A partir dessa observação, percebe-se, de antemão, a falta de engajamento e sensibilidade às questões que contemplem um ambiente pluricultural, em que as temáticas na qual relacionamse aos Direitos Humanos não caminham de forma igualitária as questões de ensino técnico, ratificando ações preconceituosas, não-igualitárias, violentas e estereotipadas. 
Ratifica-se, a relevância deste trabalho ao lançar o olhar à realidade escolar heterogênea, no que tange ao ambiente cultural e linguístico, no que diz respeito à política para mulheres no âmbito das relações entre homens e mulheres, arranjos familiares, mudanças históricas, autonomia econômica etc.

Este projeto pretende construir na formação humanística e cidadã da comunidade (interna e externa), alcançando uma formação integral que dialogue entre as disciplinas técnicas e não técnicas do ensino médio técnico integrado. Assim, espera-se o enfrentamento de ideologias e posturas, já fixadas e a desconstrução das mesmas, a fim de instaurar um ambiente pluricultural e democrático, no contexto social.

Este trabalho possibilita, também o movimento transdisciplinar de aprendizagem em que conteúdos de outras disciplinas como história, geografia, biologia, sociologia, filosofia etc, que podem vir a partilhar o mesmo espaço de aprendizagem. Dessa forma, a interdisciplinaridade estará presente na perspectiva que a realização da linguagem humana não se constitui de maneira isolada e requer aspectos biológicos, geográficos, sociológicos, históricos, filosóficos etc.

Convém ressaltar que essa proposta julga desenvolver a educação humanística em busca de direitos de igualdade, equidade, valorização de gênero, constituição identitária, formação coletiva, tolerância em diversos âmbitos sociais a fim de construir um ambiente democrático, dialético e de inclusão quanto às políticas para mulheres.

\section{Pressupostos Teóricos}

Entende-se como abordagem humanística voltada à educação como aquela que parte de três princípios: filosófico (indivíduo dotado de livre arbítrio, consciência moral, racionalidade e criatividade), sócio-político (ordem política democrática, pluralista e justa, igualdade e solidariedade) e pedagógico (ajudar o desenvolvimento das competências e habilidade dos indivíduos). Esses princípios fundamentais norteiam a educação como base de pensamento e ação de como o educador elabora as estratégias de desenvolvimento do processo de ensino-aprendizagem, ancoradas "no respeito pela vida e dignidade humanas, igualdade de direitos e justiça social, diversidade social e cultural e um sentimento de solidariedade humana e responsabilidade compartilhada por nosso futuro comum" (UNESCO, c2009). 
A partir dos quatro pilares da educação, apresentado no Relatório para a UNESCO da Comissão Internacional sobre Educação para o século XXI, em 1998, escrito por Jacques Delors, tem-se em vista que o educando precisa

- Aprender a conhecer - um amplo conhecimento geral, com a oportunidade de aprofundar um pequeno número de matérias.

- $\quad$ Aprender a fazer - adquirir não apenas habilidades profissionais, mas também a competência para lidar com muitas situações e trabalhar em equipes.

- $\quad$ Aprender a ser - desenvolver a própria personalidade e ser capaz de agir com maior grau de autonomia, julgamento e responsabilidade pessoal.

- $\quad$ Aprender a viver juntos - desenvolver uma compreensão do outro e uma apreciação da interdependência.

Assim, este projeto visa o desenvolvimento de ações humanísticas que fundamente os pilares educacionais. É papel do professor criar condições de desenvolver os saberes citados acima para que o discente saiba situar-se no próprio mundo e em outros mundos, contribuindo para uma formação válida, crítica e útil.

A maneira de desenvolvimento dessas ações tange aos conceitos de educação plurilingue e pluricultural. Essas concepções teóricas partem do entendimento de que é necessária uma educação pluri - lingue e cultural para oportunizar a igualdade e o respeito entre a comunidade escolar e o respeito à pluralidade, num plano democrático e dialógico.

Braga e Bizarro (2004) defendem que produzir um ambiente de pluralidade é dar voz àqueles ausentes dos conteúdos escolares, na prática escolar, como: mundo feminino, mundo rural, cultura infantil, homossexuais, classe trabalhadora, pessoas portadoras de necessidades especiais, $3^{\circ}$ idade, minorias éticas e culturais. Trazer para a escola não só a cultura dominante, é necessário, assim como, promover outras culturas que devem ter o seu espaço de convivência.

Assim, o espaço escolar torna-se frutífero à implementação do pensamento e atitude plural por oportunizar o fenômeno da interação, do diálogo, o compromisso, o saber aprender, a convivência, a valorização de SI e do OUTRO.

O plurilinguismo está em consonância com o pluriculturalismo em convergir para as práticas pedagógicas pautadas no mosaico cultural, social, étnico, racial, político, vigente no 
século XXI. Os espaços pluri (s) estão lado a lado na constituição da identidade do indivíduo no processo de re/conhecimento do outro, a partir da relação dialógica.

Portanto, este projeto e proposta preveem, no âmbito da pesquisa, explorar a competência múltipla dos alunos no que diz respeito ao repertório linguístico-cultural a fim de explorar realidades culturais, linguísticas, étnicas, migratórias, minoritárias e raciais; princípios de justiça, igualdade, liberdade, responsabilidade e tolerância; dimensões históricas, econômicas, políticas, estéticas, religiosas, morais e ecológicas, com finalidades de tomar consciência da dignidade humana, respeito à diferença, inclusão, democracia participante e diversidade.

Vê-se, no Quadro Europeu Comum de Referência de Línguas (QECR, 2001, p. 23), a abordagem plurilinguística

[...] acentua o facto de que, à medida que a experiência pessoal de um indivíduo no seu contexto cultural se expande, da língua falada em casa para a da sociedade em geral e, depois, para as línguas de outros povos (aprendidas na escola, na universidade ou por experiência directa), essas línguas e culturas não ficam armazenadas em compartimentos mentais rigorosamente separados; pelo contrário, constrói-se uma competência comunicativa, para a qual contribuem todo o conhecimento e toda a experiência das línguas e na qual as línguas se interrelacionam e interagem.

O documento ainda aborda que no ambiente plurilinguístico o contexto pluricultural aparece, ou seja, há uma coexistência de competências em que a cultura não é apenas um elemento inserido na língua ou vice-versa, mas sim um sistema orgânico.

\section{Metodologia}

A metodologia que sustenta este trabalho pauta-se na pesquisa-ação na compreensão de que é uma forma de investigação que promove novos "observadores", curiosos e questionadores, além de desenvolver a ação, análise e atitude colaborativa com a análise reflexiva. A pesquisa-ação, neste trabalho, aliado a etnografia e auto-etnografia propõem ao considerar, como atitude principal, a dimensão cultural na descrição e análise reflexiva, na percepção do papel do pesquisador e pesquisado. Assim, acreditamos que a junção das metodologias constitui de forma produtiva o trabalho e se encaixa nos objetivos do estudo.

\section{Proposta humanística: política para mulheres}

O contexto do estudo é o ambiente escolar, no nível do ensino médio e ainda integrado ao ensino técnico, na região centro-oeste do Paraná. O projeto, juntamente, com a proposta, pretende contribuir na formação humanística e cidadã da comunidade (interna e externa), 
alcançando uma formação completa entre o diálogo entre as disciplinas técnicas e não técnicas do ensino médio técnico integrado. Assim, espera-se o enfrentamento de ideologias e posturas, já fixadas e a desconstrução de outras, a fim de instaurar um ambiente pluricultural e democrático, no contexto social.

A motivação surge da percepção, como professora-pesquisadora, no ambiente escolar, atitudes preconceituosas, machistas, sexistas e intolerância em diversos momentos nas aulas de línguas, materna e estrangeiras. Além do contexto, do quantitativo baixo de mulheres no corpo discente, muito caracterizado por ser um ensino técnico integrado ao ensino médio, na área tecnológica, de informática, numa primeira percepção da manutenção do discurso das áreas de exatas e tecnológicas não serem áreas dominadas pelo gênero feminino, ainda nos dias de hoje. E, também, o contexto de poucas mulheres no corpo docente. Diante dessas contestações, percebe-se a pertinência da proposta em que a voz da mulher e sua representatividade devem ter espaço nesse e em outros ambientes.

O processo de implementação da proposta se inicia com a seleção da bolsista para a proposta. A exigência, que cabe explicitar, é a de gênero, ou seja, que a bolsista fosse do gênero feminino ou que se reconhece ao gênero feminino por conta da oportunidade de dar voz e representatividade à mulher, no ambiente escolar. Houve um processo seletivo com alguns critérios inerentes à bolsa, além da exigência da escrita de um texto na qual a candidata deveria escolher um tema para discorrer. Seguem os temas:

- Mulheres não devem ser discriminadas no mercado e suas oportunidades não devem ser limitadas aos papéis de gênero que a sociedade impõe sobre elas;

- Não é obrigação da mulher cuidar da casa, dos filhos e do marido. Os afazeres domésticos e cuidado com as crianças devem ser de igual responsabilidade para homens e mulheres.

- Nenhuma mulher é uma propriedade. Nenhum homem tem o direito de agredir fisicamente ou verbalmente uma mulher, ou ainda determinar o que ela pode ou não fazer;

- O corpo da mulher é de direito somente da mulher. A ela cabe a sua sexualidade como bem entender, decidir como vai dispor de seu corpo e da imagem, com quem ou como vai se relacionar;

- Qualquer ato sexual sem consentimento é estupro. Nenhum homem tem o direito de dispor sexualmente de uma mulher contra a vontade dela; 
- Nunca é culpa da vítima;

- Assédio de rua é uma violência. A mulher tem o direito ao espaço (e também) ao transporte público) sem ser constrangida, humilhada, ameaçada e intimidada por assediadores.

Após a seleção da bolsista, a segunda etapa da proposta foi criar um coletivo de mulheres na instituição com a proposta de sororidade, reflexão e ações que pudessem oportunizar a consciência sobre a temática de gênero, o direito das mulheres e outras questões pertinentes ao contexto, além do escolar.

A criação do coletivo teve resistência por parte das próprias meninas, na qual muitas relataram que não tinham interesse em participar da proposta por não se interessarem pelo tema central ou que tinham receio em participar pelas crenças e/ou falta de conhecimento de termos como feminismo, sexismo etc. Foram realizados diversos convites as meninas para formação do coletivo, sempre esclarecendo o objetivo do trabalho.

O coletivo de alunas foi criado com a participação de 7 (sete) meninas que enfrentaram o primeiro desafio ao definir em um estatuto qual era o papel e objetivo deste grupo. Assim, o processo de consolidação do trabalho deu-se com a elaboração do estatuto. Após algumas reuniões, alguns pontos conflitantes foram levantados pelo grupo, como: o vocábulo menina e mulher.

Os vocábulos menina e mulher foram discutidos no que tange ao seu conceito na representação desse grupo. As pesquisas realizadas em diversos dicionários indicavam: (i) menina 1. criança do sexo feminino. 2. Mulher jovem. (ii) mulher 1. Pessoa do sexo feminino. 2. Mulher quando deixa de ser virgem. 3. Condição de menina que entra na puberdade. 4. Esposa, amante, companheira. 5. Pessoa do sexo feminino em idade adulta (AULETE, 2013). As discussões realizadas partem do papel social da mulher de esposa, amante e companheira presente do conceito do vocábulo mulher. Assim, o grupo acordou que se sentia mais confortável em direcionar o grupo as denominações como um coletivo de meninas pelo vocábulo menina não carregar os papéis sociais já pré-estabelecidos pela sociedade até os dias de hoje.

Outra discussão gerada na elaboração do estatuto do coletivo partiu dos deveres das participantes no que se refere à preservação das questões discutidas, respeito à opinião alheia e experiências das integrantes do grupo e, acima de tudo, o não julgamento nas exposições e discussões. 
Nas reuniões do coletivo, foram levantadas ao longo de meses algumas questões que todas elencaram como necessárias às discussões, à observação e à preocupação de gênero no mundo contemporâneo. São elas: (i) dificuldades de mulheres ocuparem empregos com melhores salários, níveis hierarquias e altos níveis de escolaridade? (ii) diferença de ocupação de homens e mulheres nos espaços do mercado no trabalho? (iii) em que momento social, histórico e político passou a ser discutido política para mulheres? (iv) como você se sente em situação vulnerável no dia a dia? (v) qual o limite entre flertar, assediar e elogiar? Essas questões foram levantadas para nortear nossos trabalhos teóricos e práticos ao longo da duração da proposta.

Realizamos, também, discussões sobre o nome do coletivo, a fim de dar visibilidade e criar uma identificação as ações do grupo. Nomeamos o grupo de Programadas para questionar pelo contexto de serem futuras programadoras, já que realizam o curso de Técnico em Informática, e as meninas almejarem evidenciar a presença do gênero feminino no curso predominante do gênero masculino, além do espaço para discussões de gênero nesse contexto escolar.

Ao longo das reuniões foram percebidas diversas falas das meninas em relação à proposta. Algumas falas partem do preconceito e falta de conhecimento da proposta pautada em discutir gênero, como "não aceitação do projeto" por parte de muitos da comunidade escolar, meninos e meninas. Outras falas surgem da pertinência da temática no ambiente escolar, "importância de um coletivo na escola" e "importância em participar do coletivo". Além das falas da organização e formação de uma "ação coletiva". E, também, questões relacionadas às preocupações com crenças e estereótipos que o coletivo objetiva questionar e, talvez, modificar paradigmas enraizados em diversos ambientes sociais, "crenças, estereótipos e paradigmas a serem quebrados com o coletivo".

Vale destacar ações educativas práticas que foram realizadas no ambiente escolar. A primeira, na Mostra Científica e Cultural de 2018, elaboramos uma dinâmica a fim de conscientizar sobre o preconceito de gênero enraizado em nossa língua, na reprodução automática de crenças, estereótipos, preconceito e intolerância. Essa dinâmica foi realizada com alunos internos e externos do instituto, na visita de escolas municipais e estaduais do município de Quedas do Iguaçu, de níveis fundamental I e II, ensino médio e jovens e adultos (EJA), aproximadamente, 500 (quinhentos) estudantes participaram em 2 (dois) dias de mostra. 
O coletivo Programadas para questionar escreveram diversos cartazes com frases do senso comum e enraizadas em nossa cultura, como: "Lugar de mulher é na cozinha", "Mulher no volante, perigo constante", "Mulher não deve vestir roupa curta", "Essa mulher deve estar na TPM" etc. Essas frases foram dispostas em cartazes na sala de aula da dinâmica. Os participantes leram as frases e aqueles que nunca pensaram ou disseram tais frases deveriam entrar em um quadrado, localizado no chão no centro da sala. Após essa ação as organizadoras da dinâmica explicavam o objetivo da dinâmica. E apresentavam o vídeo da campanha HeforShe, promovida pela ONU (Organização das Nações Unidas) no âmbito global que retrata uma fala da atriz Camila Pitanga direcionada aos homens que, também, devem ser agentes na luta de igualdade de gênero em diversos espaços e não reprodutores dos discursos expostos na dinâmica. A partir da observação da dinâmica, contestamos que muitos não se deram conta da reprodução dos discursos, outros não admitiram tais pensamentos, poucos admitiram nunca terem reproduzido as frases e muitos se sentiram intimidades com a proposta abordada.

A segunda ação foi realizada no $\mathrm{SEPIE}^{2} \mathrm{X}$ (Seminário de Pesquisa, Inovação, Ensino e Extensão do Campus Quedas do Iguaçu) em que foi apresentado o trabalho acadêmico em forma de pôster, intitulado "As vozes das meninas de Quedas do Iguaçu: uma pesquisa intercultural e humanística". A apresentação foi uma das formas de divulgar o trabalho realizado pelo coletivo, além de esclarecer dúvidas e trazer conhecimento sobre o tema. Além do pôster, foram expostos cartazes com frases em que os alunos receberam de forma anônima no ambiente escolar que muitos alunos se sentiram assediados. Frases como "Minha cama perguntou se você quer dormir comigo" e "Amanhã às 10 horas no banheiro". Essas frases foram expostas com o objetivo de expor à comunidade escolar essa problemática e gerar reflexão sobre assédio, cantadas, invasão de privacidade etc. A repercussão foi muito satisfatória, na questão, que muitos alunos relataram que não se sentiam confortáveis e pensaram o motivo dessa ação anônima e invasiva.

\section{Conclusões}

Este trabalho encontra-se em andamento, com previsão de conclusão em julho de 2019, com proposta de renovação. Ainda estão previstas algumas ações no projeto no projeto, como um curso de extensão em que objetiva abordar o sexismo presenta na linguagem, relacionando-se diretamente com as bases históricas e culturais da nossa sociedade. Além da elaboração de um material de conscientização, gênero cartilha, sobre um viés temático que 
estamos debruçadas "Qual o limite entre flertar, assediar e elogiar?” nas discussões teóricas e elaborações de ações práticas, no presente momento.

O projeto humanístico, assim, como a proposta de política para as mulheres, busca conquistar seu espaço no contexto escolar a fim de trazer questões de gêneros, ou seja, questões de minorias para a constituição de um ambiente de pluralidade social, cultural e linguística em que pilares como a solidariedade, empatia, equidade e responsabilidade sejam praticados em diversos espaços em nossa sociedade.

\section{Referências bibliográficas}

AULETE, Caldas. Aulete de bolso: dicionário de língua portuguesa. - Porto Alegre, RS: L\&PM; Rio de Janeiro: Lexikon, 2013.

BIZARRO, R.; BRAGA, F. Educação intercultural, competência plurilíngue e competência pluricultural: novos desafios para a formação de professores de línguas estrangeiras. In: SECÇÃO DE ESTUDOS FRANCESES DO DEPARTAMENTO DE ESTUDOS PORTUGUESES E DE ESTUDOS ROMÂNICOS (Org.). Estudos em homenagem ao Professor Doutor António Ferreira de Brito. Porto: Faculdade de Letras da Universidade do Porto, 2004. p. 57-69.

BRASIL. Paramêtros Curriculares Nacionais (PCNs). Língua Portuguesa. Ensino Fundamental. Terceiro e quarto ciclos. Brasília: MEX/SEF, 1998.

CONSELHO DA EUROPA. Quadro Europeu Comum de Referência para as Línguas: aprendizagem, ensino e avaliação. Trad. de Maria Joana P. do Rosário e Nuno V. Soares. Porto, Portugal.: Edições ASA, 2001.

ORGANIZAÇÃO DAS NAÇÕES UNIDAS PARA A EDUCAÇÃO, A CIÊNCIA E A CULTURA (UNESCO). Relatório Mundial da UNESCO Investir na diversidade cultural e no diálogo intercultural. Brasília: UNESCO BRASIL, c2009.

ORGANIZAÇÃO DAS NAÇÕES UNIDAS PARA A EDUCAÇÃO, A CIÊNCIA E A CULTURA (UNESCO). Repensar a educação: Rumo a um bem comum mundial? Brasília: UNESCO BRASIL, 2016. 